\title{
Paternalistik Liderliğin Hizmet İnovasyon Davranışı Üzerine Etkisinin ve İş Tatmininin Aracılık Rolünün Yapısal Eşitlik Modellemesi ile Test Edilmesi \\ (Impact of Paternalistic Leadership on Service Innovation Behavior and the Mediating Role of Job Satisfaction with Testing of Structural Equation Modeling)
}

\author{
Ahmet YILDIZ (iD) a Erhan EKİNGEN (iD) b \\ a Batman Üniversitesi, Sağlık Yüksekokulu, Sağlık Yönetimi Bölümü, Batman, Türkiye. ahmet.yildiz@batman.edu.tr \\ b Batman Üniversitesi, Sağlık Yüksekokulu, Sağlık Yönetimi Bölümü, Batman, Türkiye. erhan.ekingen@batman.edu.tr
}

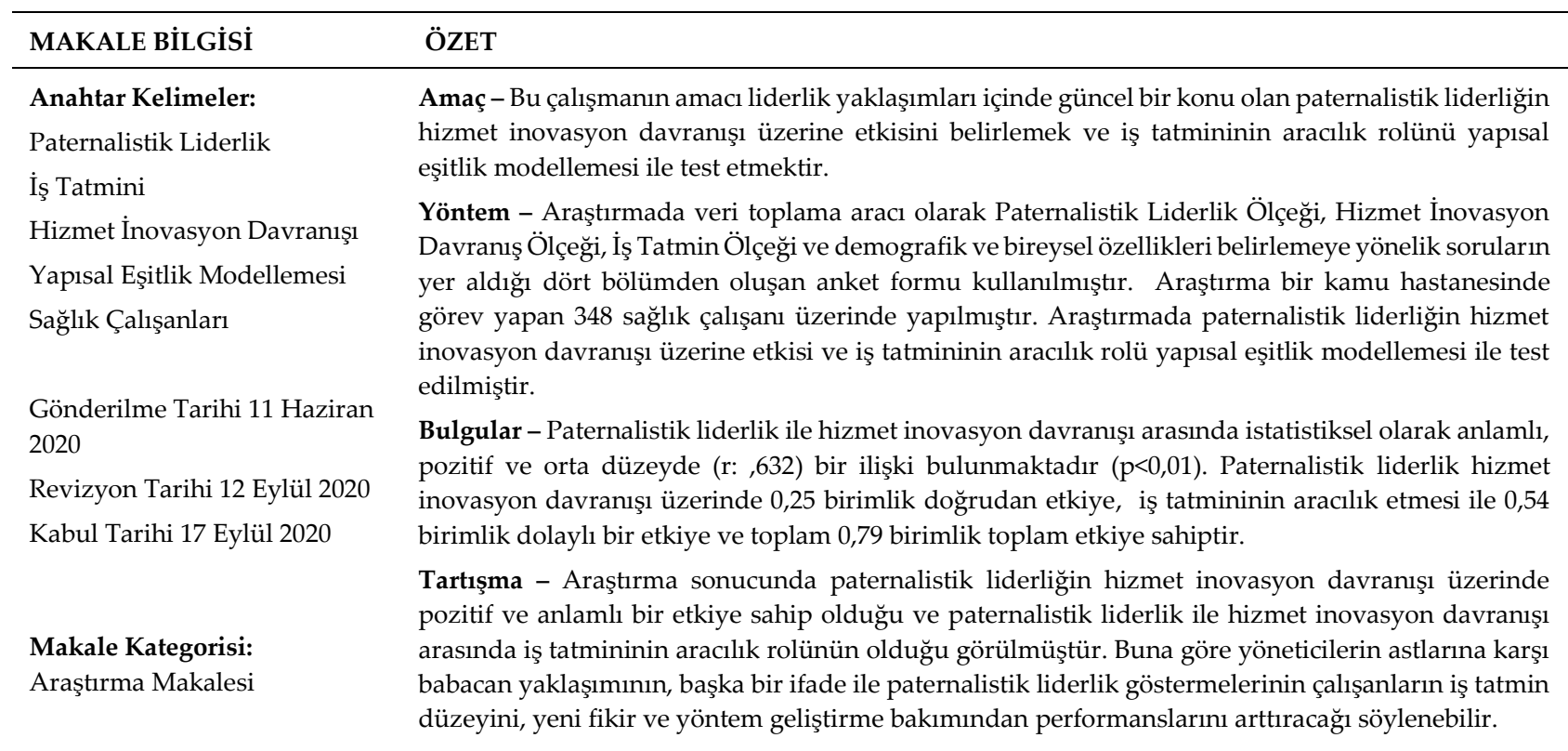

\begin{tabular}{l} 
ARTICLE INFO \\
\hline Keywords: \\
Paternalistic Leadership \\
Job Satisfaction \\
Service Innovation Behavior \\
Structural Equation Modeling \\
Healthcare Professionals
\end{tabular}

Received 11 June 2020

Revised 12 September 2020

ABSTRACT

Purpose - The aim of this study is to determine the effect of paternalistic leadership, which is a current subject in leadership approaches, on service innovation behavior and to test the mediating role of job satisfaction with structural equation modeling.

Design/methodology/approach - In the study, a questionnaire form consisting of four parts, namely Paternalistic Leadership Scale, Service Innovation Behavior Scale, Job Satisfaction Scale, and questions to determine demographic and individual characteristics were used as data collection tool. The research was conducted on 348 healthcare professionals working in a public hospital. The effect of paternalistic leadership on service innovation behavior and the mediating role of job satisfaction was tested by structural equation modeling.

Findings - There is a statistically significant, positive and moderate (r: 632) relationship between paternalistic leadership and service innovation behavior $(p<0.01)$. Paternalistic leadership has a direct effect of 0.25 units on service innovation behavior, an indirect effect of 0.54 units with the mediation of job satisfaction, and a total effect of 0.79 units.

Article Classification:

Discussion - As a result of the research, it has been observed that paternalistic leadership has a positive and significant effect on service innovation behavior and job satisfaction has a mediating role between paternalistic leadership and service innovation behavior. Accordingly, it can be said that the paternalistic approach of the managers to their subordinates, in other words, their paternalistic leadership will increase the job satisfaction level of the employees and increase their performance in the development and of new ideas and methods.

\section{Önerilen Atıf/ Suggested Citation}

Yıldız, A., Ekingen, E. (2020). Paternalistik Liderliğin Hizmet İnovasyon Davranışı Üzerine Etkisinin ve İş Tatmininin Aracılık Rolünün Yapısal Eşitlik Modellemesi ile Test Edilmesi, İşletme Araştırmaları Dergisi, 12 (3), 2916-2926. 


\section{A. Y1ld1z - E. Ekingen 12/3 (2020) 2916-2926}

\section{GİRIŞ}

Hızla değişen dünyamızda mal veya hizmet üreten tüm işletmelerin değişimlere ayak uydurmaları kaçınılmaz bir hal almıştır. Değişime hızlı bir şekilde ayak uydurmanın en etkin yolu da işletmenin elinde bulundurduğu insan kaynağını etkin ve verimli bir şekilde kullanmasıdır. Hizmet üreten işletmelerdeki insan kaynağının üretim aşamasında daha etkin rol alması çalışan davranışlarının önemini daha fazla arttırmaktadır. Yöneticilerin sergilediği liderlik tarzı ve çalışanların iş tatmin düzeyleri, çalışan davranışları üzerinde etkilidir. İşletmelerin hedeflerine ulaşmalarındaki temel unsurlardan biri de çalışanların tutum ve davranışlarıdır. Çalışanların tutum ve davranışlarını etkileyen temel unsurlar içinde yer alan yöneticilerin sergilediği liderlik yaklaşımları ve çalışanların iş tatmin düzeyleri araştırmacılar için önemli çalışma alanları içerisinde yer almaktadır.

Son on yılda, Hindistan ve Çin gibi yeni sanayileşmiş ülkeler, teknolojik yenilik ve yabancı iş yatırımlarında güçlü oyuncular olarak ortaya çıktı. Batı dışı kültürlere artan iş ilgisi, bu kültürlere özgü liderlik tarzlarına akademik ilgiyi de ateşledi. Paternalistik (babacan) liderlik yeni bir kavram değildir ve geleneksel Çin Konfüçyüsçülük felsefesine dayanmaktadır. Konfüçyüsçülük, kolektivist ve yüksek güçlü uzak kültürlerde yaygın bir felsefedir ve ahlak, nezaket, otoriteye ve saygıya dayanan yukarıdan aşağıya hiyerarşik bir sistemin önemini vurgular (Bedi, 2020). Paternalistik liderlik, Batı kültürlerinde geliştirilenlerden çok farklı bir liderlik tarzıdır. Geleneksel Çin kültüründe derin bir şekilde kök salmıştır. Konfüçyüsçülüğün "ren (iyilik)" boyutunu "wei (otoriterlik)" ve "de (ahlak)" düşünceleriyle bütünleştirir. Bu liderler güçlü bir otoriteye ve başkaları üzerinde mutlak güce sahiptirler, astlarından uzak dururlar ve gerçek hislerini ve niyetlerini gizleme eğilimindedirler. Bu davranışlar astlarına karşı korku uyandırır ve itaatlerini güçlendirir. Ancak aynı zamanda, paternalistik liderler, astlarına gerçek bir nezaket ve bütüncül bir özen gösterirler, böylece astları için minnettarlık ve borçluluk yaratır, bu da onların itaatlerini daha da güçlendirebilir. Dahası, paternalistik liderler, üstün kişisel erdemler, yüksek dürüstlük, öz disiplin ve özveriliğe sahip olan astları için bir rol model görevi görürler. Paternalistik liderlik "güçlü disiplin ve otoriteyi kişisel bir atmosferde ifade eden babacan yardımseverlik ve ahlaki bütünlükle birleştiren" bir tarz olarak tanımlanmıştır. Bu tanıma göre, paternalistik liderlik üç unsurdan oluşur. Bunlar otoriterlik, yardımseverlik ve ahlaki liderliktir (Hou vd., 2019).

Paternalistik liderlik, Ebeveyn (baba) ve çocuk arasında beklenen tipik ilişkiye dayanmaktadır Paternalistik liderlik tarzı liderlerin hem iş yerinde hem de iş dışında çalışanların iyiliği için samimi ilgi gösteren, çalışanları üzerinde otorite kuran ve kontrolü açıç̧a elinde tutan davranışlar ile karakterizedir. (Hiller vd., 2019). Başka bir anlatımla paternalistik liderlik yöneticilerin disiplin ve otoritesini babacan bir yardımseverlikle harmanlaması ve ortaya koymasıdır (Gerçek, 2018). Liderlik yaklaşımları ile ilgili yapılan akademik çalışmalarda yer alan paternalistik liderlik kavramına Silin (1976)' in Tayvan' da yapmış olduğu araştırma öncülük etmiştir. Çalışmada doğrudan paternalistik liderlik kavramı tanımlanmasa da paternalistlik liderliğin özellikleri tanımlanmıştır. Paternalistik liderlik yardımseverliği, ahlaki dürüstlüğü ve otoriteyi içinde barındıran bir liderlik tarzıdır (Türesin-Tetik ve Köse, 2015).

Asya ve Ortadoğu ülkeleri ile batı ülkelerindeki yöneticilerin sosyal ve kültürel değerlerin farklılaşmasından dolayı farklı liderlik yaklaşımları sergiledikleri birçok araştırmacı tarafından ifade edilmiştir (Farh ve Cheng, 2000). Kültürel bir değer olarak Pasifik Asya, Orta Doğu ve Latin Amerika topluluklarında karşımıza çıkan paternalizm, işletmelerde çalışanlarını koruyan, ihtiyaçlarını karşılayan ve onlar için en doğru kararı vereceğine inanılan bir liderlik yaklaşımına dönüşmüştür. Çin, Hindistan ve Türkiye gibi Ortadoğu ve Asya ülkeleri ile Latin Amerika ülkelerinde paternalistlik liderlik yaklaşımının tercih edildiği görülmektedir (Salminen-Karlsson, 2015). Aycan vd. (2000) tarafından yapılan araştırmada da Çin, Pakistan Hindistan ve Türkiye'nin paternalistik liderliğin en çok gözlemlendiği ülkeler olduğu ifade edilmiştir. Paternalistik yaklaşımın tercih edildiği ülkelerde çalışanlar, korunan, gözetilen ve aile ortamına benzeyen örgütlerde çalışmak istemektedirler (Wasti, 2000) ve bu örgütlerdeki paternalistik liderlik yaklaşımı çalışanların örgüte olan bağlılıklarını arttırmak ile birlikte örgüt çıktıları üzerinde pozitif bir etki yaratmaktadır.

Çalışanların iş tatminin hem etkilenen hem de etkileyen rolde olması işletme çıktıları üzerindeki etkisini artırmaktadır. Yöneticilerin tutum ve davranışları iş tatmini üzerinde oldukça etkilidir. Yapılan çalışmalarda, ücret gibi önemli bir motivasyon kaynağının az olduğu iş ortamlarında bile yöneticilerin liderlik yaklaşımlarının iyi olması, iş tatminini olumlu yönde etkilemektedir. Bu durum yönetim tarzının iş tatmini üzerinde etkili olduğunu göstermektedir (Bozkurt, Bozkurt 2008). Yapılan araştırmalarda yöneticilerin liderlik 


\section{A. Y1ld1z - E. Ekingen 12/3 (2020) 2916-2926}

tarzının iş tatmin düzeyini ve işletme çıktılarını etkilediği gibi iş tatmin düzeyinin de işletme çıtıları üzerinde etkilerinin olduğu görülmüştür (Chiok Foong Loke, 2001; Hamidifar, 2010; Ahmad vd., 2013; Bozkurt ve Bozkurt, 2008).

İnsan unsurunun daha etkin rol oynadığı hizmet sektöründe, yöneticilerin liderlik tarzları ve çalışanların iş tatmin düzeyleri çıtılar üzerinde daha önemli etkiye sahiptir. Hizmet işletmelerinde hizmetlerin devamlılı̆̆ını ve rekabet avantajını sağlayan en önemli unsurlardan biri de işletmeyi ve müşterilerini en iyi şekilde tanıyan çalışanların yeni hizmetler geliştirmek için sergileyecekleri davranışlardır (Sürücü ve Şeşen, 2019). Bu nedenle hizmet sektöründe yer alan işletmelerde hizmet inovasyon davranışını etkilediği düşünülen paternalistik liderlik ve iş tatmin düzeyi araştırma değişkenleri arasında yer almıştır. Hizmet inovasyon davranışı, çalışanların performanslarının artması ile birlikte işleriyle ilgili yeni fikirler bulmaları, bu fikirleri sunmaları ve gerçekleştirmeleri şeklinde tanımlanmaktadır. Hizmet inovasyon davranışı yeni fikirlerin ortaya çıkmasında ve gerçekleştirmesinde çalışanların ortaya koyduğu tepki ve davranışlardır (Çetinkaya vd., 2018).

$\mathrm{Bu}$ araştırmada liderlik yaklaşımları içinde yer alan paternalistik liderliğin, hizmet inovasyon davranışı üzerine etkisi ve iş tatmininin aracılık rolü yapısal eşitlik modellemesi kullanılarak analiz edilmiştir. Çalışma sağlık çalışanları üzerinde yapılmıştır. Sağlık hizmeti üreten kuruluşlardaki çalışanların iş tatmin düzeyleri ve yöneticilerin liderlik yaklaşımları, hizmeti alanlarla doğrudan temas halinde olan sağlık çalışanlarının sunmuş oldukları hizmet çıktılarını etkileme gücünün daha yüksek olması çalışmanın sağlık çalışanları üzerinde yapılmasının önemini artırmaktadır.

\section{YÖNTEM}

\subsection{Araştırmanın Amacı ve Hipotezleri}

$\mathrm{Bu}$ araştırmanın amacı, paternalistik liderliğin hizmet inovasyon davranışı üzerine etkisini ve iş tatminin aracılık rolünü belirlemektir. Bu amaç doğrultusunda oluşturulan araştırma modeli Şekil 1'de sunulmuş ve araştırma hipotezleri aşağıdaki gibi belirlenmiştir.

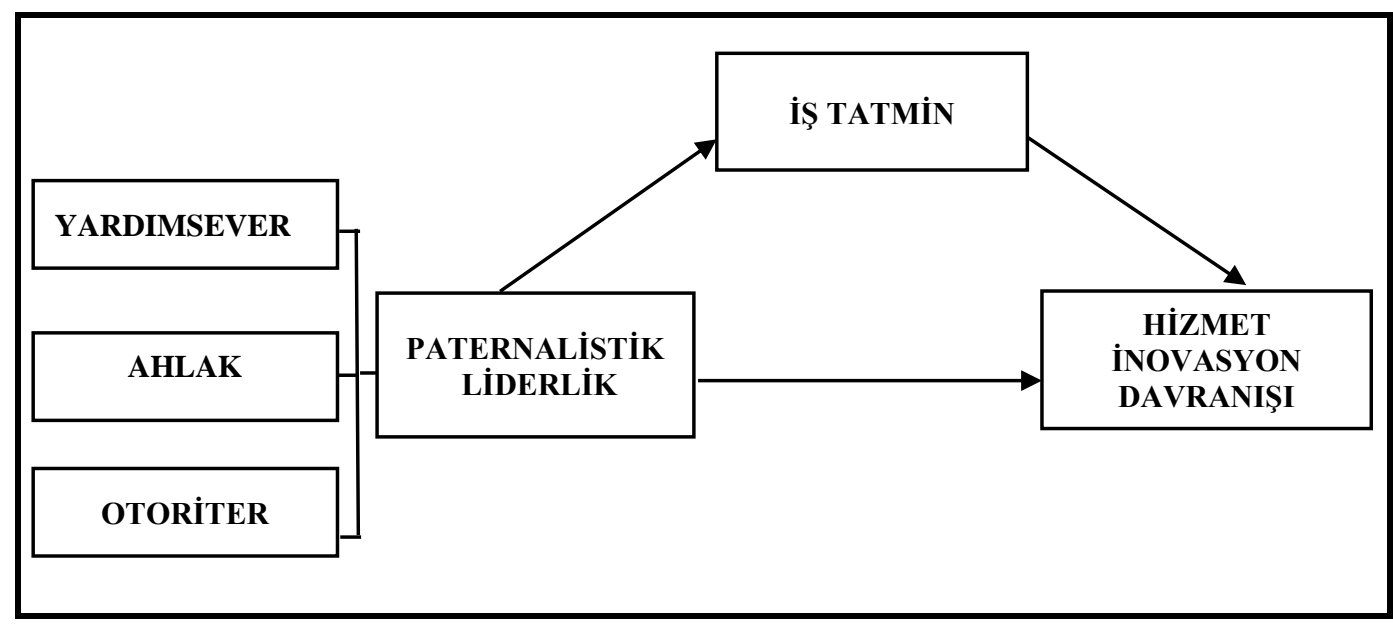

Şekil 1. Araştırma Modeli

H1: Paternalistik liderlik, hizmet inovasyon davranışı üzerinde pozitif ve anlamlı bir etkiye sahiptir.

H2: Paternalistik liderlik, iş tatmini üzerinde pozitif ve anlamlı bir etkiye sahiptir.

H3: İş tatmini, hizmet inovasyon davranışı üzerinde pozitif ve anlamlı bir etkiye sahiptir.

H4: Paternalistik liderliğin hizmet inovasyon davranışı üzerindeki etkisinde iş tatminin aracılık rolü vardır.

\subsection{Evren, Örneklem ve Ölçüm Araçlar}




\section{A. Y1ld1z - E. Ekingen 12/3 (2020) 2916-2926}

Araştırma evreni, bir kamu hastanesinin klinik birimlerinde görev yapan sağllk çalışanlarından (doktor, hemşire, acil tıp teknisyeni, laborant, radyoloji teknisyeni, tıbbi sekreter, sağlık memuru) oluşmaktadır. Araştırma yapılan hastane Batman ilinde bulunan, genel hastane statüsünde, temel tıp uzmanlık alanlarının bulunduğu ve özellikli birimleri (yoğun bakım, ameliyathane vb.) olan bir hastanedir. Hastanenin klinik birimlerinde aktif görev yapan 709 sağlık çalışanı bulunmaktadır. Araştırmada örneklem seçilmemiş olup araştırmaya katılmayı kabul eden tüm sağlık çalışanları (348 kişi) araştırmaya dahil edilmiştir 15.03.2020 tarihli ve 229 sayılı Etik kurul izni ve idari izin alındıktan sonra araştırmaya başlanılmıştır.

Araştırmada kullanılan Paternalistik Liderlik Ölçeği Cheng vd. (2004) tarafından geliştirilmiş olup, Erol ve Şentürk (2018) tarafından Türkçeye uyarlanarak geçerlilik ve güvenirlik çalışması yapılmıştır. Toplam 26 (yirmi altı) maddeden oluşan ölçek yardımseverlik (11 madde), ahlak (6 madde) ve otoriter (9 madde) olmak üzere üç faktörlü bir yapıya sahiptir. Ölçek maddelerinin puanlandırılmasında önceki araştırmacılar tarafından da kullanılan $6^{\prime}$ lı likert ölçeğinden faydalanılmıştır. Erol ve Şentürk (2018) tarafından yapılan çalışmada ölçeğin güvenirlik katsayıları (Cronbach alfa) yardımseverlik boyutu için 0,93; ahlak boyutu için 0,91 ; otoriter boyutu için 0,92 olarak hesaplanmıştır. Ölçeğin toplam güvenirlik katsayısı ise 0,80 bulunmuştur. Çalışmamızda güvenirlik katsayıları; yardımseverlik boyutu 0,88; ahlak boyutu 0,93; otoriter boyutu 0,85 ve ölçeğin toplam güvenilirlik katsayısı 0,90 olarak hesaplamıştır.

İş tatmin ölçeği, Hackman ve Oldham'in (1975) tarafından geliştirilmiş olup, Şeşen (2010a) tarafından Türkçe uyarlaması yapılmıştır. Beş madden oluşan ölçeğin güvenirliği Şeşen (2010a) tarafından yapılan çalışmada 0,78 olarak hesaplanmış ve tek faktörden oluştuğu belirtilmiştir. Ölçek maddelerinin puanlandırılmasında 5'li likert ölçeğinden faydalanılmıştır. İş tatmin ölçeğine ait güvenirlik katsayısı (Cronbach alfa) 0,81 olarak hesaplamıştır.

Hizmet inovasyon davranışını değerlendirmek için Monica Hu vd. (2009) tarafından geliştirilen Karadal ve Özsungur (2017) ve Ekingen vd., (2018) tarafından yapılan araştırmalarda kullanılan Hizmet İnovasyon Performans Ölçeğinin bir alt boyutu olan hizmet inovasyon davranış ölçeğinden yararlanılmıştır. Ölçek maddelerinin puanlandırılmasında 6 'lı likert ölçeği kullanılmıştır. Hizmet inovasyon davranış ölçeğinin geçerlilik ve güvenirliği Karadal ve Özsungur (2017) tarafından yapılan araştırmada test edilmiş, ölçeğin güvenirlik katsayısının 0,89 ve tek faktörden oluştuğu ifade edilmiştir. Hizmet inovasyon davranış ölçeğine ait güvenirlik katsayısı çalışmamızda 0,84 olarak hesaplanmıştır.

\section{BULGULAR}

Katılımcıların mesleki-demografik özellikleri ve araştırmada yer alan değişkenlere göre puan dağılımı Tablo 1'de gösterilmiştir. Tablo 1'e göre katılımcıların önemli bir kısmı $(\% 57,2)$ 30-40 yaş aralığındadır. Ayrıca katılımcıların yarısından fazlası (\% 53,6) erkektir.

Eğitim durumlarına bakıldığında lisans mezunlarının ağırlıkta $(\% 37,6)$ olduğu görülmektedir. Katılımcıların önemli bir kısmı $(\% 60,6)$ yardımcı sağlık personeli olarak görev yapmaktadır. Araştırmaya katılanların yarısından fazlası $(\% 53,5)$ 4-6 yıl arasında araştırmanın yapıldığı kurumda çalışmaktadır. 
A. Y1ld1z - E. Ekingen 12/3 (2020) 2916-2926

Tablo 1. Katılımcıların Demografik-Mesleki Özellikleri ve Değişkenlere Göre Puan Dağılımı

\begin{tabular}{|c|c|c|c|c|c|c|c|c|}
\hline \multirow[b]{2}{*}{ Değiş̧kenler } & \multirow[b]{2}{*}{$\mathbf{n}$} & \multirow[b]{2}{*}{ Yüzde } & \multicolumn{2}{|c|}{$\begin{array}{l}\text { PATERNALISSTIK } \\
\text { LİEER }\end{array}$} & \multicolumn{3}{|c|}{ İŞ TATMİN } & \multirow{2}{*}{$\frac{\text { HID }^{*}}{\text { SS }^{\mathrm{b}}}$} \\
\hline & & & Ort. $^{a}$ & $\mathbf{S S}^{\mathbf{b}}$ & Ort. ${ }^{a}$ & $\mathrm{SS}^{\mathrm{b}}$ & Ort. ${ }^{a}$ & \\
\hline \multicolumn{9}{|l|}{ Yaş } \\
\hline $20-30$ & 84 & 24,1 & 3,04 & 0,59 & 3,48 & 0,57 & 3,57 & 0,50 \\
\hline $31-40$ & 199 & 57,2 & 3,21 & 0,71 & 3,51 & 0,59 & 3,68 & 0,73 \\
\hline $41-50$ & 65 & 18,7 & 3,14 & 0,73 & 3,39 & 0,62 & 3,56 & 0,72 \\
\hline \multicolumn{9}{|l|}{ Cinsiyet } \\
\hline Kadın & 185 & 53,6 & 3,05 & 0,71 & 3,54 & 0,57 & 3,66 & 0,67 \\
\hline Erkek & 163 & 42,4 & 3,16 & 0,66 & 3,39 & 0,60 & 3,60 & 0,70 \\
\hline \multicolumn{9}{|l|}{ Eğitim } \\
\hline Meslek Lisesi & 52 & 14,9 & 3,07 & 0,61 & 3,39 & 0,54 & 3,34 & 0,73 \\
\hline Ön lisans & 72 & 20,7 & 3,06 & 0,68 & 3,50 & 0,55 & 3,71 & 0,42 \\
\hline Lisans & 131 & 37,6 & 3,14 & 0,69 & 3,49 & 0,63 & 3,63 & 0,72 \\
\hline Lisansüstü & 93 & 26,4 & 3,30 & 0,73 & 3,45 & 0,59 & 3,73 & 0,74 \\
\hline \multicolumn{9}{|l|}{ Görev } \\
\hline Doktor & 62 & 17,8 & 3,38 & 0,85 & 3,49 & 0,65 & 3,81 & 0,78 \\
\hline Yrd. Sağ. P.* & 211 & 60,6 & 3,11 & 0,60 & 3,47 & 0,56 & 3,57 & 0,63 \\
\hline Diğer* & 75 & 21,6 & 3,10 & 0,75 & 3,44 & 0,63 & 3,67 & 0,73 \\
\hline \multicolumn{9}{|l|}{ Çalışma Süresi } \\
\hline $0-3$ & 56 & 16,0 & 3,15 & 0,69 & 3,38 & 0,57 & 3,45 & 0,69 \\
\hline $4-6$ & 186 & 53,5 & 3,12 & 0,66 & 3,43 & 0,60 & 3,65 & 0,69 \\
\hline $7-9$ & 106 & 30,5 & 3,24 & 0,74 & 3,59 & 0,59 & 3,70 & 0,64 \\
\hline
\end{tabular}

* HiD: Hizmet İnovasyon Davranışı, Yrd. Sağ. P.: Yardımcı Sağlık Personeli (Hemşire, Sağlık Memuru, Acil Tip Teknisyeni), Diğer: Laborant, Radyoloji Teknisyeni, Tibbi Sekreter, aOrtalama, bStandart Sapma

Ölçeklere ait Doğrulayıcı Faktör Analizinde (DFA), uyum indeks değerlerine göre faktör yükü düşük olan maddeler ölçeklerden çıkarılmış ve programın önerdiği modifikasyon önerileri de dikkate alınarak ölçeklere ait analizler tamamlanmıştır. Paternalistik liderlik ölçeği için yapılan DFA analiz sonucuna göre yardımseverlik alt boyutundan 2 (iki) madde, ahlaki alt boyutundan 1 (bir) ve otoriterlik boyutlarından 2 (iki) adet olmak üzere toplam 5 (beş) madde ölçekten çıkarılmıştır. Paternalistik liderlik ölçeğinde yardımsever, ahlaki ve otoriter boyutlarında ikişer madde Programın önerdiği modifikasyon önerileri de dikkate alınarak birleştirilmiştir ve ölçeğe son hali verilmiştir. Ölçeklere ve yapısal modellemeye ait uyum indeks değerleri Tablo 2' de verilmiştir. Tablo 2'ye göre paternalistik liderlik ölçeğine ait uyum indeks değerleri incelendiğinde ölçeğe ait uyum indeks değerlerinin kabul edilebilir ve iyi uyum değerleri arasında olduğu görülmektedir. İş tatmin ölçeğine ait uyum indeks değerlerinin kabul edilebilir ve iyi uyum değerleri arasında olması ve ölçeğe ait maddelerin faktör yüklerinin yeterli olmasından dolayı ayrıca madde çıkarma veya birleştirme işlemi yapılmamıştır. Aynı şekilde hizmet inovasyon davranışı ölçeğine ait maddelerde de çıarma veya birleştirme işlemi, DFA analiz sonuçlarına göre indeks değerlerinin kabul edilebilir ve iyi uyum değerleri arasında olması ve faktör yüklerinin yeterli olmasından dolayı yapılmamıştır. Araştırmada kullanılan her bir ölçek için DFA yapıldıktan sonra ölçeklere son hali verilmiş ve ölçekler araştırma için tasarlanan yapısal eşitlik modeline aktarılmıştır. 
A. Y1ld1z - E. Ekingen 12/3 (2020) 2916-2926

Tablo 2. Değişkenlere ve Modele Ait Uyum İndeks Değerleri

\begin{tabular}{lllllllll}
\hline & $\chi^{2}$ & SD & X2/sd & RMSEA & CFI & IFI & GFI & AGFI \\
\hline PL & $362^{*}$ & 183 & $1,97^{\mathrm{a}}$ & 0,03 & $0,95^{\mathrm{b}}$ & $0,95^{\mathrm{a}}$ & $0,91^{\mathrm{a}}$ & $0,89^{\mathrm{b}}$ \\
IT & $15,928^{* *}$ & 5 & $3,18^{\mathrm{b}}$ & $0,07^{\mathrm{b}}$ & $0,97^{\mathrm{a}}$ & $0,95^{\mathrm{a}}$ & $0,98^{\mathrm{a}}$ & $0,94^{\mathrm{a}}$ \\
HíD & $20,95^{* *}$ & 9 & $2,32^{\mathrm{a}}$ & $0,06^{\mathrm{b}}$ & $0,98^{\mathrm{a}}$ & $0,98^{\mathrm{a}}$ & $0,98^{\mathrm{a}}$ & $0,95^{\mathrm{a}}$ \\
MODEL & $736,428^{* *}$ & 456 & $1,61^{\mathrm{a}}$ & $0,04^{\mathrm{a}}$ & $0,95^{\mathrm{b}}$ & $0,95^{\mathrm{a}}$ & $0,88^{\mathrm{a}}$ & $0,87^{\mathrm{b}}$ \\
\hline
\end{tabular}

PL: Paternalistik Liderlik; İT: İş tatmin; HİD: Hizmet İnovasyon Davranışı; a İyi Uyum Değeri; ${ }^{b}$ Kabul Edilebilir Uyum Değeri, ${ }^{*} \mathrm{p}<0,05,{ }^{* *} \mathrm{p}<0,01$

Tablo 3. Korelasyon ve Güvenirlik Analiz Değerleri

\begin{tabular}{lllllllll}
\hline & Ort. & SS & $\mathbf{1}$ & $\mathbf{2}$ & $\mathbf{3}$ & $\mathbf{4}$ & $\mathbf{5}$ & $\mathbf{6}$ \\
\hline 1. Paternalistik Liderlik & 3.16 & .69 & $(.90)$ & & & & & \\
2. Yardımsever & 3.43 & .57 & $.577^{* *}$ & $(.88)$ & & & & \\
3. Ahlak & 3.01 & .91 & $.796^{* *}$ & $.359^{* *}$ & $(.93)$ & & & \\
4. Otoriter & 2.80 & .70 & $-551^{* *}$ & $-580^{* *}$ & $-332^{* *}$ & $(.85)$ & & \\
5. İş Tatmini & 3.47 & .59 & $.501^{* *}$ & $.566^{* *}$ & $.288^{* *}$ & $-618^{* *}$ & $(.81)$ & \\
6. HíD & 3.63 & .68 & $.632^{* *}$ & $.583^{* *}$ & $.415^{* *}$ & $-676^{* *}$ & $.603^{* * *}$ & $(.84)$ \\
\hline
\end{tabular}

**p< 0,01 (Çift yönlü); N: (348) Not: Ölçeklere ait Cronbach alfa katsayıları parantez içinde verilmiştir.

Araştırma değişkenlerine ait kolerasyon ve güvenirlik analiz sonuçları Tablo 3'te verilmiştir. Tablo 3 incelendiğinde paternalistik liderlik ile hizmet inovasyon davranışı arasında istatistiksel olarak anlamlı, pozitif ve orta düzeyde (r: ,632) bir ilişkinin olduğu görülmektedir $(\mathrm{p}<0,01)$. Yardımseverlik $(\mathrm{r}:, 583)$ ve ahlak boyutları (r: ,415) ile hizmet inovasyon davranışı arasında pozitif, orta düzeyde, otoriter boyut ile hizmet inovasyon davranışı (r: -,676) arasında ise negatif ve orta düzeyde anlamlı bir ilişkinin olduğu görülmektedir $(\mathrm{p}<0,01)$.

Paternalistik liderlik ile iş tatmini arasında istatistiksel olarak anlamlı, pozitif ve orta düzeyde (r: ,501) bir ilişki bulunmuştur $(\mathrm{p}<0,01)$. Yardımseverlik boyutu ile iş tatmini $(\mathrm{r}$, ,566) arasında güçlü, ahlak boyutu ile iş tatmini $(\mathrm{r}:$,288) arasında ise zayıf düzeyde, pozitif ve istatistiksel olarak anlamlı bir ilişki olduğu görülmüştür $(\mathrm{p}<0.01)$. Otoriterlik boyutu ile iş tatmini $(\mathrm{r}:-, 618)$ arasında ise negatif ve orta düzeyde bir ilişkinin olduğu görülmüştür $(\mathrm{p}<0,01)$. İş tatmini ile hizmet inovasyon davranışı arasında da istatistiksel olarak anlamlı, pozitif ve orta düzeyde (r: ,603) bir ilişki bulunmuştur $(\mathrm{p}<0,01)$.

Yapısal eşitlik modellemesi Şekil 2'de gösterilmiştir. Modele ilişkin uyum indeks değerleri kabul edilebilir ve iyi uyum değerleri arasında bulunmuştur (Tablo 2). Modelde, paternalistik liderliğin hizmet inovasyon davranışı üzerinde iş tatminin aracılık rolü test edilmiştir. Aracılık rolünün ispat edilmesi için bazı koşulların sağlanması gerekir. İlk önce bağımsız değişkenin bağımlı ve aracı değişken üzerine etkisi daha sonra aracı değişkenin bağımlı değişkene etkisi ayrı ayrı test edilir. Daha sonra araştırma modeline göre aracı değişken modele dahil edilir. Aracılık rolünden bahsedilebilmesi için bağımsız değişkenin, bağımlı değişken üzerindeki etkisi düşerken, aracı değişkenin bağımsız değişken üzerinde anlamlı bir etkiye sahip olması gerekir (Baron ve Kenny 1986; Meydan ve Şeşen, 2011; Gürbüz, 2019).

Bu bilgiler ışığında iş tatminin aracılık rolünü test etmek için paternalistik liderliğin, iş tatmini $(\beta: 0,90 ; p<0,01)$ ve hizmet inovasyon davranışı $(\beta: 0,85 ; p<0,01)$ üzerindeki etkisi ayrı ayrı test edildikten sonra iş tatminin hizmet inovasyon davranışı $(\beta: 0,72 ; p<0,01)$ üzerine etkisi test edilmiştir. Bir sonraki aşamada iş tatmini değişkeni modele aracı değişken olarak eklenmiştir. Modelde paternalistik liderliğin hizmet inovasyon davranışı üzerine etkisinin düştüğü $(\beta: 0,25)$ ve iş tatminin hizmet inovasyon davranışı üzerinde anlamlı bir etkiye sahip olduğu görülmüştür $(\mathrm{p}<0,01)$. 


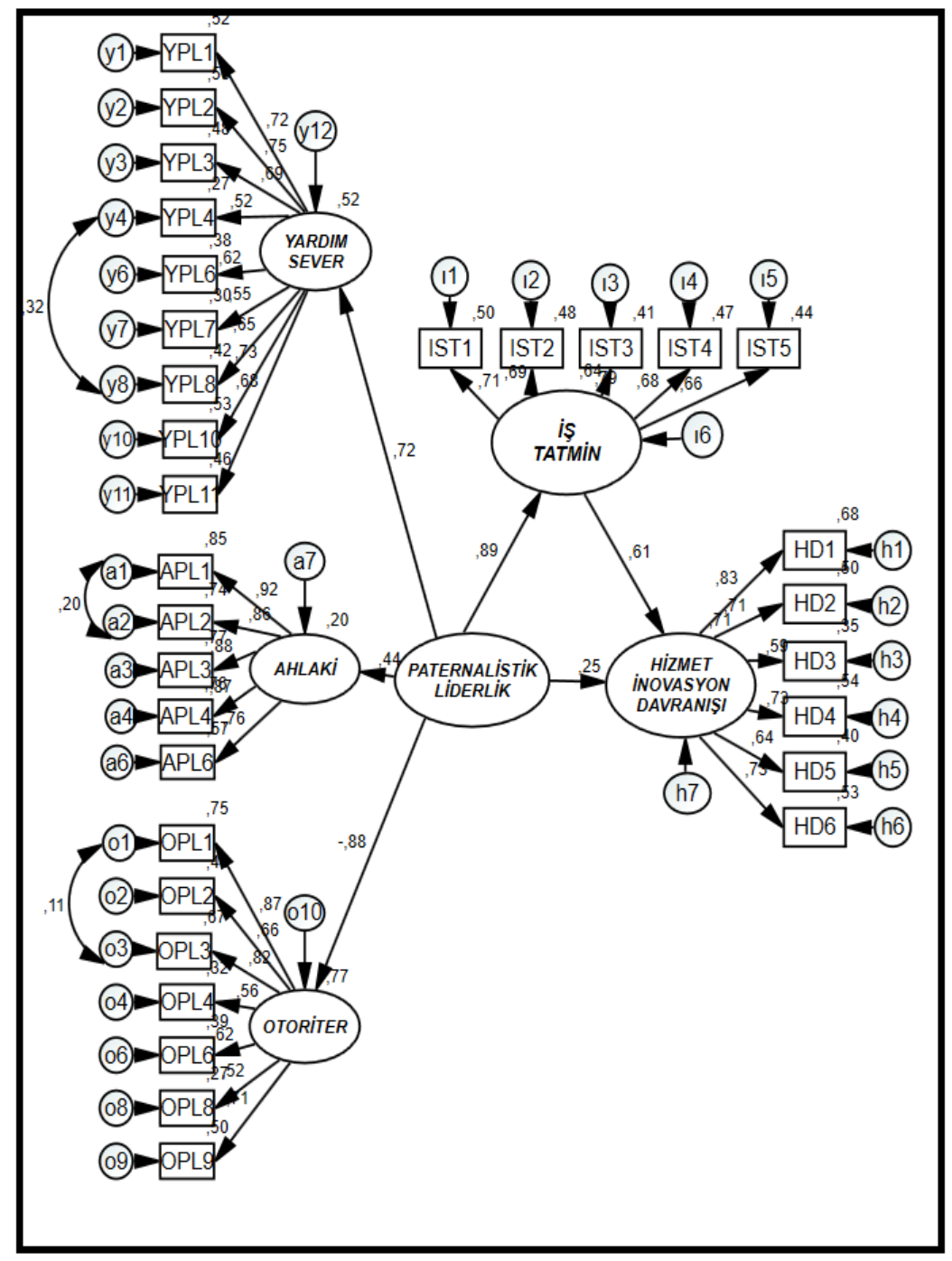

Şekil 2: Araştırmaya ait yapısal eşitlik modellemesi

$\mathrm{Bu}$ sonuçlara göre patarnalistik liderlik ile hizmet inovasyon davranışı ilişkisinde iş tatmininin aracılık rolünün olduğu söylenebilir. Yapısal eşitlik modeli analiz sonuçlarına göre H1, H2, H3 ve H4 hipotezleri kabul edilmiştir.

Tablo Hata! Belgede belirtilen stilde metne rastlanmadı.: Doğrudan, Dolaylı ve Toplam Etkiler

\begin{tabular}{ccccc}
\hline $\begin{array}{c}\text { Bağımsız } \\
\text { Değişkenler }\end{array}$ & $\begin{array}{c}\text { Bağımlı } \\
\text { Değişkenler }\end{array}$ & Doğrudan Etki & Dolaylı Etki & Toplam Etki \\
\hline PL & HiD & 0,25 & $0,89 * 0,61=0,54$ & 0,79 \\
IT & & 0,61 & - & 0,61 \\
\hline
\end{tabular}

PL: Paternalistik Liderlik; İT: İş tatmin; HİD: Hizmet İnovasyon Davranışı;

Paternalistik liderliğin hizmet inovasyon davranışı üzerindeki doğrudan, iş tatmininin aracılık etmesi ile ortaya çıan dolaylı ve toplam etkileri Tablo 4 'te verilmiştir. Tablo 4 incelendiğinde, paternalistik liderliğin hizmet inovasyon davranışı üzerinde 0,25 birimlik doğrudan etkiye sahipken, iş tatmininin aracıllk etmesi ile 0,54 birimlik dolaylı bir etkiye ve toplam 0,79 birimlik toplam etkiye sahip olduğu görülmektedir.

\section{SONUÇ VE TARTIŞMA}

Bu çalışmada paternalistik liderliğin hizmet inovasyon davranışı üzerine etkisi ve iş tatminin aracılık rolü araştırılmıştır. Araştırma sonucunda iş tatminin paternalistik liderliğin hizmet inovasyon davranışı üzerine etkisinde aracılık rolünün olduğu görülmüştür. Hizmet sektöründe çalışanların iş tatmin düzeyleri ve 


\section{A. Y1ld1z - E. Ekingen 12/3 (2020) 2916-2926}

yöneticilerin tutum ve davranışları hizmet inovasyon davranışları üzerinde önemli bir etkiye sahiptir. Sağlık hizmetlerinde hizmeti üretenlerin doğrudan çalışanlar olması bu çalışmanın önemini artırmaktadır. Yöneticilerin beklenilen tutum ve davranışları sergilemeleri, çalışanların yeterli iş tatmin düzeyinde olmaları işe olan bağlılıklarını ve motivasyonlarını arttırarak yeni hizmetler üretmelerine destek olacaktır.

Araştırma sonuçlarına göre paternalistik liderliğin hizmet inovasyon davranışını etkilediği, alt boyutlardan ahlak ve yardımseverlik ile hizmet inovasyon davranışı arasında pozitif ve anlamlı bir ilişkinin olduğu, otoriterlik ile hizmet inovasyon davranışı arasında ise negatif ve anlamlı bir ilişkinin olduğu görülmüştür. Yapılan literatür taramasında ilgili konuda yapılan araştırmalarında benzer sonuçların elde edildiği görülmüştür. Chen vd. (2014) tarafından yapılan çalışmada paternalistik liderliğin üç boyutunun da çalışan performansı ile ilişkili olduğu, yardımseverlik ve ahlak boyutlarının çalışan performansı arasında pozitif, otoriterlik boyutu ile çalışan performansı arasında ise negatif bir ilişkinin olduğu ifade edilmiştir. Kurt (2013) tarafından yapılan bir araştırmada da paternalistik liderliğin yardımseverlik boyutu ile çalışanların işlerine yaratıcı katılım algıları arasında pozitif ve anlamlı bir ilişki olduğu ve otoriter boyutu ile yaratıcı katılım algısı arasında düşük düzeyde negatif ve anlamlı ilişki olduğu belirlenmiştir. Cheng vd., (2004) ve Aslan (2015) tarafından yapılan çalışmalarda paternalistik liderliğin çalışan performansı üzerine olumlu etkisi olduğu, Tekin (2019) tarafından yapılan çalı̧̧mada ise paternalistik liderliğin çalışan performansını kısmen etkilediği, Aycan (2006) tarafından yapılan çalışmada paternalistik liderlik ile otoriter liderlik türleri arasında negatif yönlü bir ilişki olduğu ve Sheer (2010) tarafından yapılan bir çalışmada paternalistik liderliğin otoriter boyutu ile çalışanların işe yaratıcı katılım davranışı arasında negatif bir ilişkinin olduğu belirlenmiştir. Sağlık çalışanları üzerinde yapılan çalışmalarda da benzer sonuçlar elde edilmiştir. Uysal vd. (2012) tarafından sağlık çalışanları üzerinde yapılan bir çalışmada çalışanların paternalistik liderlik algısının iş üretkenliğini artırdı̆̆ı belirtilmiştir. Yaman (2011) tarafından 301 sağlık çalışanı üzerine yapılan bir çalışmada sağlık çalışanlarının paternalistik liderlik boyutlarından iyiliksever ve ahlaki liderlik davranışlarının, sağlık çalışanlarının iş performansı üzerinde pozitif etkisinin olduğu belirlenmiştir. Buna göre sağlık kurumlarında yöneticilerin çalışanlarına karşı yardımsever olmaları, ahlaki davranmaları çalışan davranışlarını olumlu yönde etkileyebileceği söylenebilir.

Araştırmada paternalistik liderliğin iş tatmini üzerinde de etkisinin olduğu görülmüş̧tür. Ahlak ve yardımseverlik ile iş tatmini arasında pozitif ve anlamlı bir ilişki olduğu, otoriterlik ile iş tatmini arasında negatif bir ilişkinin olduğu belirlenmiştir. Araştırma bulguları daha önce yapılmış çalışma bulgularıyla paralellik göstermektedir. Yapılan araştırmalar liderlik tarzının iş tatmini üzerinde etkisinin olduğunu göstermektedir. Chiok Foong Loke (2001) tarafından Singapur'da hemşireler üzerinde yapılan araştırmada, Ahmad vd. (2013) tarafından Malezya' da sağlık çalışanları üzerinde yapılan araştırmada ve Hamidifar (2010) tarafından İran'da yapılan bir çalışmada, liderlik tarzı ile iş tatmini arasında anlamlı bir ilişkinin olduğu görülmüştür. Yapılan araştırmalarda liderlik yaklaşımları arasında yer alan paternalistik liderlik tarzının da iş tatmini üzerinde etkisinin olduğu görülmüştür (Pellegrini ve Scandura 2006; Tekin 2019; Uysal vd., 2012; Köksal 2011). Pellegrini ve Scandura (2006), Türkiye'de İstanbul ve Gebze'deki beş farklı sektörde çalışanları kapsayan araştırma sonucunda, paternalistik liderlik ile iş tatmini arasında pozitif ilişki olduğunu, Uysal vd. (2012) hastane çalışanları üzerinde yaptıkları çalışmada, paternalistik liderlik algısının iş üretkenliğini artırdığını ifade etmişlerdir. Benzer şekilde Köksal (2011) kültürel bir yaklaşım olarak ifade ettiği paternalistik liderliğin iş tatmini ve çalışan performansında bir artış yarattığını, Tekin de (2019) paternalistik liderliğin iş tatmini üzerinde olumlu ve anlamlı bir etkiye sahip olduğunu ifade etmişlerdir. Uçar (2019) tarafından yapılan çalışmada paternalistik liderliğin yardımseverlik ve ahlak boyutlarının iş tatmini arasında pozitif bir ilişki olduğu, otorite ve iş tatmini arasında ise negatif bir ilişki olduğu belirtilmiştir. Buna göre yöneticilerin paternalistik liderlik tarzını benimsemelerinin çalışanların iş tatmin düzeylerini artırdığı söylenebilir.

Araştırmada iş tatmininin hizmet inovasyon davranışı üzerinde anlamlı ve pozitif bir etkininin olduğu görülmüştür. Korkmazer ve Ekingen (2017) iş tatminin çalışanların verimliliğini artırdığını ifade etmişlerdir. Niu (2014) Tayvan'da beş hizmet sektörü üzerinde yapmış oluğu çalışmada iş tatmininin inovasyon davranışını olumlu yönde etkilediğini ifade etmiştir. Şeşen (2010b) tarafından hizmet sektöründe yapılan bir araştırmada, iş tatmini ile hizmet inovasyonu arasında anlamlı ve pozitif yönlü bir ilişki olduğu ve iş tatmininin iç girişimci davranışını da etkileyebileceği belirtilmiştir. Meydan (2011) iş tatminin çalışanların iç girişimcilik davranışları ile anlamlı ve pozitif bir ilişkisi olduğunu ifade etmiştir. 


\section{A. Y1ld1z - E. Ekingen 12/3 (2020) 2916-2926}

Sağlık sektöründe ve diğer sektörlerde yapılan birçok araştırmanın sonucuna göre paternalistik liderliğin birçok örgütsel değişken üzerinde olumlu etkiler yaptığ görülmektedir (Kılınç, 2018). Ayrıca iş tatminin örgütsel değişken üzerinde aracılık rolü ile ilgili çalışmaların da olduğu belirlenmiştir. Kahya (2013) iş tatminin, örgütsel sinizm ve iş performansı arasında aracılık rolünün olduğu, Anafarta (2016) örgütsel destek ve işten ayrılma niyeti arasında iş tatmininin aracılık etkisinin olduğunu ifade etmişlerdir. Benzer şekilde Gürbüz vd. (2010) örgütsel faktörler ile iç girişimcilik davranışı arasında iş tatminin aracılık etkisinin olduğunu, Şeşen (2010b) adalet algısı ile tükenmişlik davranışı ilişkisinde iş tatminin aracılık rolünün olduğunu belirtmişlerdir.

Yapılan literatür taraması ve araştırma sonuçlarına göre paternalistik liderlik tarzının çalışanlar ve işletme çıktıları üzerinde azımsanamayacak bir etkiye sahip olduğu görülmüştür. Araştırma sonucu elde edilen bu bulgular yöneticilere önemli doneler sunmaktadır. Yöneticilerin çalışanlara karşı olan ahlaki ve yardımsever davranışları çalışanların iş tatmin düzeylerine ve yaratılmak istenen inovasyonlara katkı sağlayacaktır. Yapılan araştırma sonuçları da bunu açıkça göstermektedir. Bu bağlamda, hedefleri doğrultusunda başarıya ulaşmak isteyen, hizmet çıktılarını güçlendirme çabası içinde olan, etkililiğini ve verimliliğini artırmak isteyen hizmet işletmelerindeki yöneticilerin sergileyecekleri liderlik tarzlarının doğrudan çalışanların iş tatmini ve hizmet inovasyon davranışı üzerinde etkileri olduğunu bilerek hareket etmelidirler.

Araştırma, araştırmaya katılanların değerlendirmeleriyle sınırlıdır. Araştırma kapsamı ve geçerliliğinin artırılması için araştırmanın başka hastanelerde başka gruplar üzerinde de yapılması önerilmektedir.

\section{KAYNAKÇA}

Ahmad, A. R., Adi, M. N. M., Noor, H. M., Rahman, A. G. A., \& Yushuang, T. (2013). The influence of leadership style on job satisfaction among nurses. Asian Social Science, 9(9), 172-178.

Anafarta, N. (2015). Algılanan örgütsel destek ve işten ayrılma niyeti ilişkisi: İş tatmininin aracılık rolü. İstanbul Üniversitesi İşletme Fakültesi İşletme İktisadı Enstitüsü Yönetim Dergisi, 26(79), 112-130.

Aslan, E. (2015). Paternalist liderliğin çalışan performansına etkisinde iş ahlakının rolü. Yüksek Lisans Tezi, Beykent Üniversitesi, Ankara.

Aycan, Z. (2006). "Paternalism: Towards Conceptual Refinement and Operationalization", Yang, K.S., K. K. Hwang ve U. Kim (Ed.), Scientific Advances in Indigenous Psychologies, London, (ss. 445-466). England: Cambridge University Pres.

Aycan, Z., Kanungo, R. N., Mendonca, M., Yu, K., Deller, J., Stahl, G., \& Khursid, A. (2000). Impact of culture on human resource management practices: A ten country comparison. Applied Psychology: An International Review, 49(1), 192-221.

Baron, R. M., \& Kenny, D. A. (1986). The moderator-mediator variable distinction in social psychological research: Conceptual, strategic, and statistical considerations. Journal of personality and social psychology, 51(6), 1173.

Bedi, A. (2020). A meta-analytic review of paternalistic leadership. Applied Psychology, 69(3), 960-1008.

Bozkurt, Ö., \& Bozkurt, İ. (2008). İş tatminini etkileyen işletme içi faktörlerin eğitim sektörü açısından değerlendirilmesine yönelik bir alan araştırması. Doğuş Üniversitesi Dergisi 9(1), 1-18.

Chen, X. P., Eberly, M. B., Chiang, T. J., Farh, J. L., \& Cheng, B. S. (2014). Affective trust in Chinese leaders: Linking paternalistic leadership to employee performance. Journal of management, 40(3), 796-819.

Cheng, B. S., Chou, L. F., Wu, T. Y., Huang, M. P., \& Farh, J. L. (2004). Paternalistic leadership and subordinate responses: Establishing a leadership model in Chinese organizations. Asian Journal of Social Psychology, 7(1), 89-117.

Chiok Foong Loke, J. (2001). Leadership behaviours: Effects on job satisfaction, productivity and organizational commitment. Journal of nursing management, 9(4), 191-204. 


\section{A. Y1ld1z - E. Ekingen 12/3 (2020) 2916-2926}

Çetinkaya, N., Şimşek, A., \& Aydın, S. (2018). Duygu işçilerinin perspektifinden hizmet inovasyon davranışı: Yiyecek-içecek işletmelerine ilişkin bir araştırma, VII Ulusal III. Uluslararası Doğu Akdeniz Turizm Sетровуити, 410-421.

Ekingen, E., Ekemen, M. A., Yildiz, A., \& Korkmazer, F. (2018). The effect of intrapreneurship and organizational factors on the innovation performance in hospital. Revista de Cercetare si Interventie Sociala, 62, 196-219.

Erol, E., \& Şenturk, I. (2018). Paternalistic leadership scale Turkish adaptation: A validity-reliability study. International Journal of Educational Methodology, 4(4), 267-288.

Farh, J. L., \& Cheng, B. S. (2000). A cultural analysis of paternalistic leadership in Chinese organizations. In Management and organizations in the Chinese context (pp. 84-127). London: Palgrave Macmilla,.

Gerçek, M. (2018). Yöneticilerin babacan (paternalist) liderlik davranışlarının psikolojik sözleşme bağlamındaki beklentileri üzerindeki etkilerine yönelik bir çalışma. Eskişehir Osmangazi Üniversitesi İktisadi ve İdari Bilimler Dergisi, 13(2), 101-118.

Gürbüz, S. (2019). Amos ile Yapısal Eşitlik Modellemesi, Ankara: Seçkin Yayıncılık.

Gürbüz, S., Bekmezci, M., \& Mert, İ. S. (2010). Örgütsel faktörlerin iç girişimciliğe etkisi: İş tatminini aracı değişken mi. Organizasyon ve Yönetim Bilimleri Dergisi, 2(2), 127-135.

Hackman, J., \& Oldman, G. R. (1975). Development of the job diagnostic survey. Journal of Applied Psychology. $60(2), 159-170$.

Hamidifar, F. (2010). A study of the relationship between leadership styles and employee job satisfaction at Islamic Azad University branches in Tehran, Iran. Au-GSB e-Journal, 3(1), 45-58.

Hiller, N. J., Sin, H. P., Ponnapalli, A. R., \& Ozgen, S. (2019). Benevolence and authority as WEIRDly unfamiliar: A multi-language meta-analysis of paternalistic leadership behaviors from 152 studies. The Leadership Quarterly, 30(1), 165-184.

Hou, B., Hong, J., Zhu, K., \& Zhou, Y. (2019). Paternalistic leadership and innovation: The moderating effect of environmental dynamism. European Journal of Innovation Management. 22(3), 562-582.

Kahya, C. (2013). Örgütsel sinizm, iş performansını etkiler mi? İş tatminin aracılık etkisi. Global Journal of Economics and Business Studies, 2(3), 34-46.

Karadal, H., \& Özsungur, F. (2017). Hizmet inovasyon davranışı ile psikolojik sermaye ve etik liderlik ilişkisinin incelenmesi: Adana örneği. Uluslararası Yönetim İktisat ve İşletme Dergisi, 13(5), 663-672.

Kılınç, E. (2018). Sağlık kurumlarında paternalist liderlik modelinin incelenmesi. Journal of Healthcare Management and Leadership, (1), 1-12.

Korkmazer, F., \& Ekingen E. (2017). Örgütsel yabancılaşma'nın iş tatmini ile ilişkisi: Sağllk sektöründe bir uygulama The Journal of Academic Social Science Studies, (63), 459-470.

Köksal, O. (2014). Bir kültürel liderlik paradoksu: Paternalizm. Mustafa Kemal Üniversitesi Sosyal Bilimler Enstitüsü Dergisi, 8 (15) , 101-122.

Kurt, İ. (2013). Paternalist liderlik ile çalışanların işlerine yaratıcı katılım algıları arasındaki ilişkiyi araştırmaya yönelik bir çalışma. Sosyal ve Beşeri Bilimler Dergisi, 5(1), 321-330.

Meydan H. C., \& Şeşen, H. (2011), Yapısal Eşitlik Modellemesi AMOS Uygulamaları. Ankara: Detay Yayıncılık.

Meydan, H. (2011). İş tatmini ve öz yeterliliğin örgüt içi girişimciliğe etkisi: Kamu sektöründe bir araştırma. Journal of the Cukurova University Institute of Social Sciences, 20(1), 25-40.

Monica Hu, M.-L., Horng, J.-S., \& Christine Sun, Y.-H. (2009). Hospitality teams: Knowledge sharing and service innovation performance. Tourism Management, 30(1), 41-50.

Niu, H. (2014), Is innovation behavior congenital? Enhancing job satisfaction as a moderator. Personnel Review, $43(2), 288-302$. 


\section{A. Y1ld1z - E. Ekingen 12/3 (2020) 2916-2926}

Pellegrini, E. K., \& Scandura, T. A. (2006). Leader-member exchange (LMX), paternalism, and delegation in the Turkish business culture: An empirical investigation. Journal of International Business Studies, 37(2), 264-279.

Salminen Karlsson, M. (2015). Expatriate paternalistic leadership and gender relations in small European software firms in India. Culture and Organization, 21(5), 409-426.

Sheer, V. C. (2010). Transformational and paternalistic leaderships in Chinese organizations: Construct, predictive, and ecological validities compared in a Hong Kong sample. Intercultural Communication Studies, 19(1), 121.

Silin, R. H. (1976). Leadership and values: The organization of large-scale Taiwanese enterprises. Harvard Univ Asia Center.

Sürücü, L., \& Şeşen, H. (2019). Entrepreneurial behaviors in the hospitality industry: Human resources management practices and leader member exchange role. Revista de Cercetare si Interventie Sociala, 66, 114-132.

Şeşen, H. (2010a). Öncülleri ve sonuçları ile örgüt içi girişimcilik: Türk savunma sanayinde bir araştırma. Doktora Tezi, KHO Savunma Bilimleri Enstitüsü, Ankara.

Şeşen, H. (2010b). Adalet algısının tükenmişliğe etkisi: İş tatmininin aracı değişken rolünün yapısal eşitlik modeli ile testi. Savunma Bilimleri Dergisi, 9(2), 67-90.

Tekin, E. (2019). Paternalist liderliğin iş tatmini ve çalışan performansına etkisi üzerine bir araştırma. Third Sector Social Economic Review, 54(1), 178-204.

Türesin Tetik, H., \& Köse, S. (2015). Örgüt çalışanlarının paternalistik liderlik algıları ve öğrenilmiş güçlülük düzeyleri arasındaki ilişkilerin incelenmesi. Uluslararası Yönetim İktisat ve İşletme Dergisi, 11(26), 11-29.

Uçar, Z. (2019). Lider üye etkileşimi lensinden paternalist liderlik ve iş tatmini İlişkisi. Bitlis Eren Üniversitesi İktisadi Ve İdari Bilimler Fakültesi Akademik İzdüşüm Dergisi, 4(1) , 28-49.

Uysal, Ş., Keklik, B., Erdem, R., \& Çelik, R. (2012). Hastane yöneticilerinin liderlik özellikleri ile çalışanların iş üretkenlik düzeyleri arasındaki ilişkilerin incelenmesi. Hacettepe Să̆lık İdaresi Dergisi, 15(1) , 25-57.

Wasti, S. A. (2000). Örgütsel Bağlılı̆̆ı Belirleyen Evrensel ve Kültürel Etmenler: Türk Kültürüne Bir Bakış, Ed. Zeynep Aycan, Türkiye'de Yönetim, Liderlik ve Insan Kaynakları Uygulamaları (ss. 201-224). Ankara: Türk Psikologlar Derneği Yayınları.

Yaman, T. (2011). Yöneticilerin paternalist (babacan) lider davranışlarının çalışanların örgütsel özdeşleşmelerine, iş performanslarına ve işten ayrılma niyetlerine etkisi: özel sektörde uygulama. Yüksek Lisans Tezi, Kara Harp Okulu, Ankara. 